\title{
La narrativa de les dones a Lo Rat Penat. Calendari Llemosí (1874-1883)
}

\section{Women'snarrative in Lo Rat Penat. Calendari Llemosí (1874-1883)}

\author{
Guillem Mollà Bononad \\ Universitat de València \\ gmolla@xtec.cat
}

Data de recepció: 10/03/18

Data d'aceptació: 09/09/2018

\begin{abstract}
Resum
En aquest treball es pretén visibilitzar les dones que van publicar narrativa durant la Renaixença al País Valencià. Aquest treball és fruit d'un altre treball anterior. Però ara centrem el focus en la narrativa breu que es va publicar al País Valencià a l'anuari Lo Rat Penat. Calendari Llemosí (1874-1883), concretament hem volgut visibilitzar les dones que hi van publicar narrativa breu durant aquests anys. Cal entendre, però, aquest treball en el seu context: el circuit literari en català estava en fase embrionària, per la qual cosa no hi ha gaires publicacions. Per tant no existia la possibilitat de professionalització, de manera que molts escriptors ho eren per fer una tasca més de redreçament de la situació que per aspiracions de professionalització. D’altra banda, la llengua de la Renaixença és prenormativitzada, per la qual cosa, el model de llengua que trobem als textos serà una llengua amb vacil·lacions, que els escriptors intentaran solucionar com bonament creuran. Hem d'afegir que hi ha poques dones que publiquen, en general, en aquests anys en què el circuit literari en català estava bastint-se. Tot i això, aquesta publicació de Constantí Llombart ofereix unes poques narracions breus de dues dones. Pretenem explicar qui eren les dues escriptores que publiquen, exposar-ne el recorregut vital i classificar el tipus de narrativa que van publicar-hi. Les dones que publiquen narrativa breu a Lo Rat Penat. Calendari Llemosí (1874-1883) són Manuela Agnés Rausell i Maria de Bell-lloc. La primera d'elles publica dues peces curtes i l'última una només, al llarg dels 10 anys de vida que va tenir la publicació dirigida per Llombart.
\end{abstract}

Paraules clau: Narrativa breu, Renaixença valenciana, Literatura Femenina, Dones de la Renaixença

\begin{abstract}
In this article we want to get to know the women who were writers during the period Known as Renaissance in Valencian Country. In this article we want to focus on the short stories published in Valencian Country on Lo Rat Penat. Calendari Llemosi (1874-1883), a year book. Specifically, we want to point out the women who published short stories during this period. However, we must know these texts on its time: the catalan literary circuit was in an embryonal phase, so, there are not too much published texts. Thus, there were nothing like professional writers; indeed, that kind of work was done almost entirely for the sake of the language rather than for the writers' glory. Moreover, catalan in the Renaissance had neither grammatical, nor orthographical rules, therefore, the language of these texts has a lot of errors, but the writers would try their best. The result of these two conditions are that there are few women who have been writers in this period. However, in this publication by Constantí Llombart, we can read some short stories from two women. That is why we want to explain who they were, their biography and, also, we want to classify the kind of short stories they wrote. The women who have published short stories in Lo Rat Penat. CalendariLlemosí (1874-1883) are: Manuela AgnésRausell and Maria de Bell-lloc. The first one publishing two short stories, and the last one only one during the ten years of life of this year book.
\end{abstract}

Keywords: Short stories, Valencian Renaissance, Feminine literature, Women of the Renaissance 
$-322-$ 


\section{Taula de continguts}

1. Context de la Renaixença al País Valencià

2. Descripció de Lo Rat Penat. Calendari Llemosí (1874-1883)

3. Seccions fixes

4. Altres seccions

5. Autores a Lo Rat Penat. Calendari Llemosi

6. Narracions breus

6.1 «Un bon nadal»

6.2 «La mort d'en Ramon Boil»

$6.3 «$ Centelles y Solers ó un amor entre dos ódis»

7. Conclusions

Bibliografia 



\section{Context de la Renaixença al País Valencià}

Ens hem de situar a les acaballes del segle XIX, al període literari que coneixem com a Renaixença. És una època que donarà grans noms de la literatura catalana, com Jacint Verdaguer, Teodor Llorente, Àngel Guimerà, Narcís Oller, Constantí Llombart, etc.

La llengua catalana encara no ha passat per un procés de normativització, així doncs, cada escriptor, lletraferit o potencial usuari de la llengua escrita, ho feia com podia, com creia i no serà fins el següent segle que amb la proposta de Fabra es disposarà ja d'un model clar, uniforme i estàndard de com s'havia d'escriure en català.

És per això que podem descriure la salut lingüística, i també literària, del català com a precària si la comparem amb la resta de llengües europees, com el francès o el castellà, entre altres. A això cal sumar-li el fet que els escriptors de la Renaixença no tenien un referent literari culte proper, sinó que havien de basar-se en models del català medieval.

D’altra banda, cal afegir que no hi ha un circuit literari en català que permeta aglutinar els escriptors i promocionar-los, per la qual cosa, és impossible que es professionalitzen. De manera que, trobarem gent amb la pretensió de ser escriptor, però que per aquest handicap es dedica, alhora, a altres tasques relacionades amb el món de l'escriptura i la lectura, com per exemple editor, periodista, etc. També trobarem lletraferits, que són aquells que tot i no voler dedicar-se professionalment a l'escriptura, acaben escrivint a causa de la sensibilitat que tenen per la llengua catalana.

Cal afegir que tradicionalment s'ha explicat la Renaixença valenciana com un enfrontament intern entre dos bàndols, els conservadors, de tall més culte, liderats per Llorente, i els progressistes, de tall més popular, liderats per Llombart. En paraules de Sanchis (Sanchis, 1982: 48):

Mai no fou fàcil la col·laboració entre els dos grups de renaixentistes valencians. El de Llorente-Queroll' integraven universitaris, patricisi conservadors. El d'Escalante-Llombart era d'autodidactes, botiguer si- 
menestrals republicans. Si ho polaritzàvem, diríem que era l'eternarivalitat entre la levita i la brusa, entre el guantil'espardenya.

Aquesta visió dual de la Renaixença valenciana ha quedat refutada, en el sentit que sí bé és cert que hi havia dos bàndols, també ho és que entre ells col·laboraven. Bona prova d'això la podem resseguir en la relació de Llorente i Llombart, ja que tant l'un com l'altre van escriure en diaris o publicacions de l'altre. És més, la societat Lo Rat Penat naix amb la finalitat d'aglutinar escriptors i lletraferits de qualsevol ideologia. I si això no haguera estat així aquest projecte no s'hauria pogut donar. És a dir, a Llombart li calia l'ajuda de Llorente.

Per tant, en aquesta època trobem un context desfavorable, en principi, per al cultiu de la llengua i literatura catalana, de manera que es van haver de fer molts esforços per què això fóra possible.

\section{Descripció de Lo Rat Penat. Calendari Llemosí (1874-1883)}

Aquesta publicació, que naix de la mà de Llombart, és una desconeguda per al gran públic actual. Llombart la comença el 1874 i la presenta en forma d'anuari i miscel·lània, és a dir, un número només a l'any on es recullen textos de tipologia i gènere divers: de la narrativa al teatre, passant per l'article d'opinió, les efemèrides, els comentaris jocosos, el teatre, etc. Aquest treball de catalogació es deu a Escartí (Escartí, 2005: 152): «Hem afegit, a la fi de cada entrada, una sigla per tal d'indicar el tipus de col·laboració de què es tracta».

Ara bé, Llombart tampoc crea la publicació del no-res, cal buscar l'origen de Lo Rat Penat. Calendari Llemosí en el Calendari Català de Francesc Pelai Briz. El mèrit de Llombart és fixar-se i adaptar-lo al context valencià, com a prova de l'admiració que professava per aquesta publicació i l'èxit que havia obtingut el format a Catalunya. Això ho recull el mateix Llombart al pròleg del primer número de Lo Rat Penat. Calendari Llemosí, on explica quin serà el format i es converteix en una mena de carta de presentació al públic. En resum, Llombart analitza un producte que ja funcionava a Catalunya i l'adapta al País Valencià, tant és així que pràcticament les portades i títols de les revistes són molt similars. 
Tot i l'adaptació al context valencià, cal afegir, però, que el Calendari Català va funcionar millor que no Lo Rat Penat. Calendari Llemosí, ja que la primera va tindre més anys de vida que la segona. Aquesta darrera va ser substituïda pel Periòdich Quinzenal Literari, que, com el seu nom indica, es publicava cada quinze dies. És a dir, tot i que té menys anys de durada acaba sent substituït per una revista amb major periodicitat, la qual cosa deixa entreveure el fet que s'havia creat i començat a consolidar cert públic en llengua catalana al País Valencià.

Respecte a l'abast que va tenir Lo Rat Penat. Calendari Llemosí, en primer lloc ens hem de fixar en com l'anunciava el mateix Llombart «Compost, ab la distinguida col·laboració d'els mes reputats escriptors de Valencia, de Catalunya y de les Illes Balears per Constantí Llombart». Per tant, Llombart pretenia que l'àmbit de la publicació fóra els Països Catalans, és per això que calia comptar amb escriptors de tota la geografia. Aquest anhel de Llombart queda acomplit, tal com reporta Estrela: «Sense dubte, una de les empreses editorials més reeixides de Constantí Llombart -i per extensió de la Renaixença a València- fou Lo Rat Penat. Calendari Llemosì». (Estrela 2005: 167)

Pel que fa a la importància de la publicació en quant a qualitat i durada cal tenir en compte les paraules d'Escartí (Escartí, 2005: 138):

Lo Rat Penat, en tant que revista cultural feta des de València, però amb una clara voluntat de donar a conèixer els productes d'un costat i de l'altre de la Sénia i, encara, de les Illes Balears, va ser una de les empreses que major glòria li havia de reportar a Llombart, amb el temps. No va ser, però, fruit d'una inspiració momentània, ni tingué la brevíssima durada a què ens tenen acostumats els productes d'aquell període. Lo Rat Penat. Calendari Llemosí, és una aventura editorial que -amb ets i uts- va durar almenys deu anys, i representa, sense cap dubte, un dels majors esforços per divulgar les idees renaixencistes entre els valencians del moment.

\section{Seccions fixes}

No ens estendrem molt en aquest apartat, ja que ja l'hem tractat amb major profunditat en un altre treball. Les seccions fixes, una constant de la publicació, apareixen al llarg dels 10 anys de vida que va tenir i entre d'altres cal esmentar una de les més importants, els pròlegs, 
que escrivia el mateix Llombart -a excepció dels anys 1880 i 1881 (el 1882 el volum va ser codirigit) que li va encarregar la tasca a Josep Maria Puig i Torralba per què el primer es trobava convalescent- i en paraules de Mollà (Mollà, 2025: 393):

Al llarg d'aquests pròlegs, Llombart donava notícia dels esdeveniments lingüístics i literaris més importants d'arreu dels Països Catalans. Així doncs, podem trobar com Llombart es queixa de la situació del teatre al País Valencià, o troba esperança en la feina que s'estava fent a Catalunya per reestructurar el circuit literari, o bé reporta alguna notícia de les Illes. És també en aquesta secció on Llombart va esbossant el seu ideari, o el seu programa, per a la Renaixença.

Destaca en les seccions fixes la de les biografies, com bé diu el mateix autor (Mollà, 2015: 393):

[...]solia signar el mateix Llombart. Aquestes biografies tracten sobretot d'escriptors coetanis, tot i que també es parla d'algun escriptor del segle XVIII. Tenen una estructura fixa que sol iniciar-se amb el lloc de naixement de l'autor, un breu esbós de la infantesa, on es dóna especial importància a la formació acadèmica que va rebre i també a quin motiu va despertar la passió per l'escriptura.

Una altra de les seccions fixes, tot i que tardana, és la de les Efemèrides de València, segons l'autor (Mollà, 2015: 393):

pretén informar elslectors sobre diversos aspectes rellevants del País Valencià però sobretot de la ciutat de València. Són algunes dades realment curioses, i desconegudes també, per al públic de hui en dia.

Finalment, cal destacar a final de cada número la presència d'unes taules de conversió de mesures autòctones a mesures internacionals.

\section{Altres seccions}

Lo Rat Penat. Calendari Llemosí també compta amb altres seccions que mereixen un apartat a banda.

Com que és una miscel·lània hi apareixen gèneres textuals molt diversos, però dels que més presència té és la poesia, el producte per excel·lència del període. Segons la temàtica 
tractada, els poemes es poden encabir en tres apartats: la pàtria, la llengua i l'amor, cosa que ens evoca, inevitablement, el lema dels Jocs Florals (Patria, Fides, Amor). Per tant podem considerar la poesia que s'hi publica com a jocfloralesca.

Un altre apartat prolífic és el dels assajos, que guanya major volada als darrers números. Tot i ser de temàtica diversa els temes que més interessaven els escriptors eren la llengua i la cultura catalana.

Per tant, com veiem, aquesta publicació serveix com a primera plataforma per a crear un nucli embrionari d'escriptors i lletraferits fidels a la causa del català.

\section{Autores a Lo Rat Penat. Calendari Llemosí}

Ja hem dit que a Lo Rat Penat. Calendari Llemosí publiquen escriptors i lletraferits per cimentar les bases del català com a llengua literària i del circuit literari en aquesta llengua.

Al 1larg dels 10 anys de vida que va tindre la publicació s'ha comptabilitzat un major número d'autors que no d'autores. Segons Estrela (2013: 147): «Cent setanta-tres autors col·laboraren publicant textos al Calendari Llemosí. D’aquests, només nou són dones [...]».

És evident que apareix un major nombre d'escriptors que d'escriptores ja que a una banda trobem la feble situació de la llengua catalana i a l'altra hem d'afegir el paper social de la dona, que es veu encara relegada dels cercles literaris i de l'accés al món de la cultura, en general. La situació de la dona és marginal en el món literari i poques són les que s’atreveixen a trencar aquesta tendència.

Moltes de les escriptores que hi trobem es decanten per la poesia, però tot i que el present article tracta sobre la narrativa no és sobrer exposar unes breus dades biogràfiques d'aquestes dones per a donar-les a conèixer al gran públic. L'ordre que seguirem serà en cronològic segons vagen publicant: 
La primera autora que apareix és Victòria Penya d'Amer, pseudònim de Victòria Peña i Nicolau (Palma, 1827-Barcelona,1898) utilitza Amer ja que és el cognom del seu marit el també poeta Miquel Victorià Amer. Va participar diverses vegades als Jocs Florals arribant a obtindre un accèssit el 1859.

Maria de Bell-1loch, (Barcelona, 1841 - Barcelona, 1907) pseudònim de Maria Maspons i Labrós. Va ser una escriptora que va col·laborar a nombroses publicacions de l'època, d'entre les que destaquen Lo Gai Saber, La Renaixença, La Veu i Calendari Català. A més va publicar diversos llibres, com per exemple el volum de poesia Salabrugues (1874), i més tard la novel·la històrica Vigatans i botiflers (1878).

Anna de Valldaura (Barcelona,1853 - Barcelona, 1930) pseudònim de Joaquima Santamaria i Ventura, va col·laborar en diverses publicacions amb contes, traduccions, com per exemple el Calendari Català, Lo Gai Saber, o La Llumanera, revista que es publicava a Nova York.

Maria Josepa Massanés i Dalmau (Tarragona, 1811 - Barcelona, 1887) va escriure de ben jove, en castellà a El Vapor i El Guardia Nacional. En català va escriure alguns poemes de certa popularitat i va publicar-ne un volum: Respirall. Poesies Catalanes. Va obtindre un premi als Jocs Florals el 1864.

Manuela AgnésRausell, (València, 1839 - València, 1918) escriptora que es va adherir a la Renaixença molt aviat i va col·laborar en diferents publicacions, una d'elles era l'Almanaque de las Provincias, on participava assíduament. Va ser nombrada reina dels Jocs Florals per Constantí Llombart i té una narració premiada en aquest concurs, Centelles i Solers, ó un amor entre dos ódis (1883).

Lluïsa Duran de Leon (Barcelona, 1845 - ? Després de 1883) es va educar a la Provença i més tard es va involucrar en la vida cultural de la societat valenciana. Va publicar a revistes com La Renaixença i el Calendari Català, entre altres. 
Dolors Moncerdà de Macià (Barcelona, 1845 - Barcelona, 1919) pseudònim de Dolors Monserdà i Vidal. Va escriure en castellà fins 1875, a partir d'aquell any en català. Va participar als Jocs Florals en diverses ocasions i va guanyar el 1878, el 1882 i el 1891. Va estrenar l'obra de teatre Teresa, o un jorn de prova, amb èxit el 1875. Va publicar diverses novel·les costumistes i dos reculls de poemes. Destaca com a impulsora d'obres de caràcter social i feminista, a més de fer nombroses conferències i col·laboracions a la premsa, sobretot a La Renaixença.

Magdalena Garcia Bravo (València, 1862 - València, 1891) va col·laborar ambl'associació de Lo Rat Penat i va participar en les publicacions Lo Rat Penat. Calendari Llemosí i Lo Rat Penat: periòdich Lliterari Quinsenal.

Agnès Armengol de Badia (Sabadell, 1852 - Sabadell, 1934) va escriure poesia de caire tradicional. També va ser propagandista en favor de la integració de la dona en el moviment catalanista.

Hi ha una última escriptora de la que no hem trobat notícies, es tracta d'Encarnació de Palau i Vall-llosera, l'únic que en sabem és que es tracta d'una poetessa catalana.

El còmput global és que de les 9 dones que hi van publicar una era de les Illes, set eren de Catalunya i dues del País Valencià. Observem doncs, major presència d'autores principatines.

D’altra banda cal esmentar una dada curiosa, i és que de les 9 autores, almenys 4 van fer servir pseudònim literari.

Aquestes 9 escriptores van publicar un total de 36 textos, dels quals 33 són poemes i 3 només narracions breus. Aquesta desproporció es deu al fet que el gènere literari de la Renaixença va ser la poesia. 


\section{Narracions Breus}

Un dels apartats més destacables de Lo Rat Penat. Calendari Llemosí és el de les narracions breus, tot i no ser dels més prolífics serveix per veure en quin estat de salut es troba la prosa literària catalana.

Durant els 10 anys que va durar la publicació, hem comptabilitzat un total de 41 narracions breus, que tenint en compte les condicions precàries del català (una llengua prenormativitzada, un circuit literari totalment inexistent, la manca d'un públic lector, i uns corrents que ja estaven passats de moda a les altres literatures europees) cal dir que és un producte digne i s'ha d'estudiar i valorar en el seu context.

Pel que fa a les 41 narracions breus, n'establirem una classificació per models, i sobretot, el treball també tracta de les dones que en van escriure i publicar.

Entenem per model literari un seguit de característiques que presenta un relat i que ens permet agrupar-los mitjançant aquesta categoria.

Els models que hem comptabilitzat a Lo Rat Penat. Calendari Llemosí són cinc: el moralista, l'històric, el costumista, l'humorista i el realista. De tots aquests, els que més ens interessen són l'històric i el realista, ja que són en els que trobem 3 narracions breus de dues autores, Manuela Agnés Rausell i Maria de Bell-lloch.

Per a entrar en matèria i esclarir conceptes ens interessa saber què és una narració històrica i què és una narració realista.

Respecte al model històric oferim la definició que dóna Simbor (Simbor, 1997b: 109):

No podem seguir acceptant sense reserves la definició tradicional, ara mateix recordada, que concebia la novel·la històrica com la barreja de ficció i d'història. No, la novel·la històrica, si és novel·la, ha de ser necessària ment ficció. Això sí: una ficció amb uns lligams molt peculiars amb el món factual. Així la data, el nom propi i l'esdeveniment històrics de l'univers diegètic d'una novel·la històrica funcionen com a 
marcadors de comparació; és a dir, que el lector es veu expressament convidat a referir els enunciats a dos objectes, un dels quals és posat com a possible i l'altre com a real.

\section{I afegeix:}

El novel·lista i l'historiador comparteixen els mateixos materials (esdeveniments i personatges de períodes passats), però l'objectiu i les regles del treball són diferents.[...] El novel·lista, parteix d'un objectiu o voluntat personals, de tal manera que l'elecció dels esdeveniments respon a un criteri intencional i premeditat.

Dit d'una altra manera, el model històric és aquell en el qual el moment del relat s'ambienta en un moment determinat de la història, per la qual cosa localitzarà l'acció en un temps i un espai molt concrets, o si més no, fàcilment identificables per al lector. A més, també poden aparèixer personatges històrics famosos per dotar de versemblança el relat i fer-li creure al lector, fins i tot, que la ficció que té entre les mans va arribar a ocórrer de veritat.

Pel que fa al model realista, és el model més difícil de definir, a causa de les nombroses accepcions que s'han donat al llarg de la història de l'art, com bé descriu Georges Bafaro (Bafaro, 1995:3): «Le mot de 'réalisme' est si largement usité dans le discours de la critique d'art qu'il a fini par en devenir flou, à force d'acceptions élargies».

Tot i la crítica, també ofereix dues possibles definicions del model (Bafaro, 1995: 3):

Le mot a été pris soit en bonne soit en mauvaise part, comme le remarque le dictionnaire Robert. Selon les convictions personnelles de celui qui s'exprime, le réalisme est perçu de façon positive et s'oppose à un idéalisme qui ignorait la réalité ou manifesterait un intérêt discutable pour ce qui n’existe pas en dehors de l'imagination.

El que fa és definir-lo segons el diccionari Robert i dóna una definició per contraposició a l'idealisme. Així doncs, els textos del model realista seran aquells que s'interessen i narren fets del món real.

L’altra definició que ofereix Bafaro la deu a Champ fleury, (Bafaro, 1995: 38): 
L'écrivain doit représenter uniquement ce qu'il a vu, sans la moindre altération, sans aucune atténuation. Il lui faut donc se débarrasser de tous ses préjugés esthétiques, moraux, philosophiques, quigâteraient la spontanéité de la vision.

Le romancier ne jugepas, ne condamne pas, n'absut pas. Il expose des fait (Le Figaro, août 1856).

També afegeix el següent (1995: 58):

La volonté de raconter une histoire située dans un cadre existant, 'constatable', arrivée à des personnages de condition moyenne, voire populaire, de présenter une action sans parti-pris d'idéalisation psychologique, morale ou sociale, de refuser le travail de l'imagination, au nom de la vérité de la représentation du monde, de puiser éventuellement des sujets dans les faits divers ou la grisaille du quotidien, définit en théorie le réalisme te lqu'on le conóit à partir de 1850 .

Aquestes últimes paraules són més esclaridores, ja que explica que una novel·la realista és la que narra una història en un lloc existent. Els personatges seran un objecte de la narració, en altres paraules, no emetran cap judici sobre el món que els envolta i descriuran de manera fidedigna la realitat que veuen i viuen. En resum, el que pretén aquest model és fer creure al lector que allò que està llegint és real i ha ocorregut recentment. L'interés rau en el fet de contar les coses de la manera més objectiva possible sense cap tipus d'interferències.

\section{1 «Un bon Nadal»}

Aquesta narració, de Maria de Bell-1loc, està ambientada en una casa on hi ha diversos personatges: una mare, el marit i alguns dels fills. Al principi tots estan tristos, cadascun per diversos motius. Els fills perquè no tenen un tió per fer-lo cagar; el pare perquè els fills no el tenen; i la mare perquè té un fill a la guerra. El fill que era a la guerra torna i s'estableix un diàleg on explica que ha tornat perquè el van ferir i li han donat molt de temps perquè es cure i segons

creu no haurà de tornar a la guerra. És en aquest moment quan la tristesa s'esvaeix i porten un tió i tots són feliços. Està publicada entre les pàgines 72 i 77 del volum 3 (1876).

Aquest relat pertany al model realista. Els elements que ho demostren són diversos. En primer lloc la localització temporal que apareix és: «Era la nit de Nadál», una nit de Nadal 
que s'intenta apropar al lector perquè passa en una casa de Catalunya, com es pot deduir més endavant: «-Dónchs, ¿perque no tenim tió, ni pinyons, ni sucamuya, ni rés de lo que teniam los altres anys?». És a dir que es caracteritza la nit de Nadal com transcorreria en moltes cases catalanes d'aquella època, fins i tot el tió és una tradició que hui en dia perdura. Per tant, s'observa una reproducció de la realitat en aquest sentit.

D'altra banda, també s'anomenen uns altres indrets reals i fins i tot és ben latent la preocupació d'una mare pel seu fill: «Dias passats me varen dir que en aquells serrats de la Navarra, habian trovat no sé quans soldats gelats, qui’mdira á mi que’l meu fill no sigui an d'ells?»

Els personatges només estan descrits físicament, no tenen profunditat psicològica. Açò s'observa en la descripció del fill que ha tornat de la guerra, a la quarta pàgina:

Arribava una mica esgroguehit y flach, més per aixó, espigadet i guapo, trempat com un gíngol y mes alegre que unes pascuas: ab son vestidet de soldat, que molt rebé li esqueya, y ab sa gorreta de artillé posada un xich á la decantada que li acababa de donar tota la gracia.

En resum, les descripcions dels personatges-només físiques- el fet de no dotar-los de profunditat psicològica, així com uns comportaments universals i la descripció d'ambients i costums reals situen aquest relat en el model realista. Tots aquests elements el doten de versemblança $\mathrm{i}$ fan que puga ser una història que haja ocorregut en el món real i que per tant puga ser verídica.

\section{2 «La mort d'en Ramon Boil»}

Aquest conte de Manuela Agnés Rausell tracta de l'amor entre Mossén Joan Pertusa i una dama. Com que Joan Pertussa no li feia molt de cas a la dama, aquesta s'enamora de Ramon Boil, cosa que provoca l'enveja de Pertussa que acaba matant-lo i confessant el crim. Al final la dama mor de tristesa. Està publicat entre les pàgines 135 i 144 del volum 9 (1882). 
Aquesta narració pertany al model històric. Les dades que ho corroboren són les següents: en primer lloc, el títol és ja molt il·lustratiu «La mort d'en Ramon Boil», ja que com se sap, va existir un personatge a València amb aquest mateix nom, un governador de la ciutat que va viure fins l'any 1407 i va morir a mans de Berenguer de Reixac que va ser instigat per Joan de Pertusa.

A continuació i al principi del relat, el narrador situa l'acció en un marc temporal i espacial determinat: «En una d'aquellasapacibles vesprades de qu'enl'otony se disfruta en Valencia, allá pel mes d'octubre de l'any de gracia 1406.»

Pel que fa als personatges, a la segona pàgina ja apareix el nom de «Mossen Joan de Pertusa», personatge que com s'ha explicat anteriorment va existir en realitat. També apareix una dama, tot $\mathrm{i}$ que no serà fins la tercera pàgina que se'n revelarà el nom: «Na Margarida». És també a la tercera pàgina on apareix per primera vegada Ramon Boil: «En Ramon Boil, governador llavors de Valencia». A la pàgina cinc el narrador reporta una altra dada del període en què Ramon Boil va governar la ciutat «l'ilustre Governador [...] era aquell mateix qu'en 1397.» Mentre que a la pàgina sis segueix proporcionant informació biogràfica referent a Ramon Boil: «al ser arrivada la dels Sants Reys ó bé siga la dels 6 de Giner de 1407 [...] pogué a favor de la espesa foscor acertar al cór de l'infortunat Governador un agut colp ab una daga».

En conclusió, aquesta narració, té una sèrie d'elements com: els personatges, els anys en els quals transcorre l'acció i la localització espacial que fan que s'inscriga dins del model dels relats històrics.

L'autora ha reescrit un fet de la història local de València on ha barrejat elements reals i verídics, com ho són la mort del governador Ramon Boil, les dates en què va ser governador i el fet que Joan de Pertusa fóra un dels instigadors del seu assassinat, amb uns altres producte de la seua imaginació. El resultat d'això és una narració històrica que, com totes, crea l'efecte de versemblança en el lector i propicia que aquest puga arribar a qüestionar-se si allò és la veritat dels fets que van ocórrer. 


\section{3 «Centelles y Solers ó un amor entre dos ódis»}

Aquesta narració, també de Manuela Agnés Rausell,és com una mena de Romeu i Julieta ambientat a València. Hi ha dues famílies rivals, els Centelles i els Solers, els fills de les quals (Constanci i Blanca), es veuen d'amagat fins que un dia eviten que Constanci puga visitar a Blanca empresonant-lo en un calabós. Açò provocarà que ella acabe entrant al convent. A continuació alliberen Constanci perquè la seua estimada ha esdevingut monja. És a partir d'ací quan Constanci comença la seua venjança contra els esclaus que van ajudar els pares dels dos joves per impedir que es seguiren trobant d'amagat, i això el portarà fins el convent. Està publicada entre les pàgines $25 \mathrm{i} 37$ del volum 10 (1883).

Aquest relat pertany al model històric. Els elements que porten a pensar-ho són diversos. En primer lloc, el títol és bastant revelador, ja que és conegut que hi havia a València dues famílies històriques com són «els Centelles i els Solers». A continuació, i només començar el text, el narrador ja situa el lector en el temps i l'espai «En l'any de gràcia 1406, s’encontraba la insigne ciutat de Valencia [...]». Després presenta els caps respectius de cada família «Mosen Gilabert Centelles [...] Mosen Jaume Soler». En altres paraules, el lector té des d'un primer moment delimitat el marc temporal i espacial on es desenvoluparà l'acció i dos dels personatges amb qui l'acció estarà plenament relacionada. A més es pot dir que repeteix l'estructura de l'inici, ja que és igual que la de La mort d'en Ramon Boil, obra de la mateixa autora publicada al número anterior. A la segona pàgina passa a situar l'acció en una casa «qu'habia segut abans de la conquesta del Rey En Jaume». A més també ofereix un altre marc temporal més concret encara: «En una fresca matinada del mes d'Abril». Per tant es va d'una localització més general (la València de 1406) a una altra de més concreta (una casa de València d'estil àrab d'abans de la conquesta de Jaume I). El que fa el narrador en aquest relat és donar les coordenades espaitemps ràpidament per després passar a centrar-se directament en l'acció sense haver de fer gaire més referències a aquestes dades.

Amb tot, es pot afirmar que aquest relat entra en el prototipus del model històric, ja que l'acció s'ambienta en un temps i un espai determinats passats(la València de 1406). D'altra 
banda, el narrador, a l'hora d'anomenar els personatges, ho fa amb els dos cognoms de dues famílies molt representatives de la València d'aquella època. Fet que ajuda a dotar la narració de versemblança i pot arribar a fer que el lector es plantege si allò és producte de la imaginació de l'autora o si va ocórrer de veritat.

\section{Conclusions}

Com hem pogut veure, la Renaixença ofereix també narracions i no es limita a produir únicament poesia, tot i ser el gènere majoritari a l'època.

De la producció literària de la Renaixença cal posar de relleu la col·laboració de les dones, que com hem vist publiquen 36 textos al llarg dels 10 anys de vida de la publicació. D’aquests textos 33 són poemes, gènere per excel·lència del període. Els altres 3, textos narratius, s'insereixen en els models realista i històric, models que ja començaven a ser superats per uns altres en aquelles dates, ja que en la literatura francesa el naturalisme s'anava obrint camí de la mà de Zola i, per tant, començava a superar el realisme.

Tot i això, les dues narracions de Manuela Agnés Rausell que hem analitzat en aquest article formen part dels dos models més novedosos dins de Lo Rat Penat. Calendari Llemosí, com bé apunta Simbor (1997a: 367): «Només podem destacar dos narradors que intenten de superar el Costumisme i l'humorisme: Manuela Agnés Rausell i Vicent Blasco Ibáñez». Per tant, podríem dir que en certa manera Manuela Agnés Rausell és una modernitzadora de la manera de fer literatura en català en aquells anys. Tot i això, cal insistir que si comparem la nostra literatura amb la resta de les d'Europa, no deixa de ser una manera de fer tardana com apunta Simbor (1997: 367a): «En tot cas el recurs d'ambdós autors a la novel·la històrica no deixa de palesar l'endarreriment estético literari de l'opció, quan ja el Realisme i el Naturalisme dominaven el gènere narratiu». I afegeix també (1997a: 358): «Es tractava de començar amb obres 'festives', sense gaires escrúpols estètics, adreçades al consum d'un públic literàriament poc exigent».

Tot $\mathrm{i}$ aquest endarreriment al que fa referència Simbor cal no menystenir aquesta publicació, ja que es tracta, sens dubte, d'una de les més importants de la Renaixença valenciana, 
com a plataforma de difusió de les idees de Llombart, i és un puntal de les publicacions de l'època, prova d'això la dóna Estrela (2005: 167): «Sense dubte una de les empreses editorials més reeixides de Constantí Llombart -i per extensió de la Renaixença a València- fou Lo Rat Penat. Calendari Llemosí».

En canvi, i pel que fa a la narració de Maria de Bell-1locés una narració realista, model que ja començava a ser caduc. És lògic que siga el menys novedós, ja que també és el que apareix més aviat en la publicació. A més, només assaja fer narració en una única ocasió, cosa que provoca la tria d'un model que ja coneixia i sabia com funcionava, més que no un altre, com l'històric que demana a l'autor documentar-se sobre els fets del passat per a inserir-los en la narració i poder construir un univers diegètic versemblant.

Encara que el present treball se centra en les narracions escrites per dones, no està de demés fer unes consideracions de caràcter general que afecten totes les escriptores, tant les poetesses com les narradores.

En primer lloc, i pel que fa a les autores que hi apareixen, com hem dit, un gran nombre provenen de Catalunya, cosa que es pot deure al fet que literàriament, en aquest període, Catalunya era la punta de llança dels Països Catalans i per tant és normal que siga el territori que més autores aporte.

D’altra banda, cal destacar també el fet que almenys quatre de les nou autores opten per fer servir un pseudònim literari. De les dues autores que escriuen narrativa una en fa servir (Maria de Bell-1loc) i l'altra (Manuela Agnés Rausell) no. Aquest pseudònim, però no és un nom masculí, sinó que opten per modificar un poc el seu nom original. Podem pensar doncs, que es deu al fet de voler desvincular-se, en certa manera, del seu jo com a autora, fruit segurament de la consideració social que tenia la dona en aquell moment, privada de l'accés a la cultura i subjugada a l'home, que sí que hi tenia accés. També és curiós que moltes opten per fer servir la preposició «de» i el sentit que denota siga el de pertinença a algú o a algun lloc, cosa que té a veure també en la concepció que es tenia de la dona en aquells temps. 
Per contra, la major part de les dones fan servir el seu propi nom, pot ser degut al fet que siguen més reivindicatives? No els crea cap conflicte ni familiar, ni social presentar-se al públic lector? Quina concepció tenen del paper de la dona en la societat? Totes aquestes preguntes haurien de ser respostes en un altre treball. Tot i que tampoc no es disposa de gaire informació al respecte, fruit de la invisibilització del paper de la dona fora del tradicional.

No oblidem que ens trobem davant d'una societat marcada llargament pel pes de l'església catòlica que regia gran part dels àmbits socials, de l'opinió pública i que atorgava a la dona un paper domèstic i tenir cura de la casa, del marit i encarregar-se de la criança i educació dels fills. La dona era considerada un ésser sotmès a l'autoritat masculina: primer el pare i després el marit.

És en aquest context on trobem la figura d'aquestes dones, aquestes escriptores que traspassen els límits de la llar i exerceixen un paper que la societat no els concedia.

El paper de la Renaixença és el de regenerar la llengua i la literatura, però per a les dones podria suposar obrir la porta a renovar la societat i fer-la més moderna, justa i igualitària.

Finalment, cal afegir que aquest treball té per objecte donar a conèixer les autores de narrativa de la Renaixença i reivindicar la importància de les dones en el procés de renovació lingüística i literària i qui sap si de retruc el d'iniciar també un procés de canvi social en la concepció de la dona en aquells temps.

En resum, ens trobem amb unes dones que, destinades per l'època que els ha tocat viure, a ser invisibles a nivell cultural, aconsegueixen fugir del seu paper i presenten a Lo Rat Penat. Calendari Llemosí uns textos narratius breus, dignes i d'una certa qualitat literària.

Així, la publicació es converteix també en l'aixopluc de les dones que tenen certa ambició literària, o en paraules de Llombart «llemosinista».

D'altra banda, el treball hauria de tenir una continuïtat que analitze amb més profunditat la resta de composicions de les dones que apareixen en aquesta publicació i establisca uns models per a la poesia per a conèixer millor la importància de les escriptores en la Renaixença valenciana. 


\section{Bibliografia}

Bafaro, Georges (1995). Le roman réaliste et naturaliste. Paris: Ellipses.

Escartí, Vicent Josep (2005). «Les idees de Constantí Llombart a través de Lo Rat Penat. Calendari Llemosì» en Escartí, Vicent Josep; Roca, Rafael (Ed.) Constantí Llombart i el seu temps. València: Acadèmia Valenciana de la Llengua.

Estrela, Josep Enric (2005). «L’interés pel passat històric a Lo Rat Penat. Calendari Llemosí» en Escartí, Vicent Josep; Roca, Rafael (Ed.) Constantí Llombart i el seu temps. València: Acadèmia Valenciana de la Llengua.

Estrela, Josep Enric (2013). Escriptors i literatura al Calendari Llemosí (1874- 1883). València: Institució Alfons el Magnànim.

Lo Rat Penat. Calendari Llemosí (1875-1884), v. 1-10, col·lecció facsímils, 2. València: Publicacions de l'Acadèmia Valenciana de la Llengua.

Mollà, Guillem (2015). «Els models narratius a Lo Rat Penat. Calendari Llemosí (1874-1883)» dins Actes del XVIIé Col·loqui de l'AILC, València, pp. 391-401

Sanchis, Manuel (1982). Renaixença al País Valencià: estudi per generacions. València: Eliseu Climent.

Simbor, Vicent (1997a). «La Renaixença i la normalització literària» en Carbó, Ferran et al. Escalante i el teatre del segle XIX. València/Barcelona: Institut Interuniversitari de Filologia Valenciana Publicacions de l'Abadia de Montserrat.

Simbor, Vicent (1997b). «Sobre la novel·la històrica actual» en de Caplletra, 22. 